\title{
A EXPERIÊNCIA SUICIDA NUMA PERSPECTIVA HUMANISTA-FENOMENOLÓGICA
}

\author{
Suicide Experience in Phenomenological Humanistic Approach \\ La Experiência del Suicídio en una Perspectiva Humanista Fenomenológica
}

\author{
Marcio Arthoni Souto da Rocha \\ Georges Daniel Janja Bloc Boris
}

VIRGINIA MOREIRA

\begin{abstract}
Resumo: Esta pesquisa tem como objetivo compreender a experiência suicida a partir de um referencial humanista-fenomenológico que propõe uma revisão conceitual da psicologia humanista de Carl Rogers a partir da fenomenologia da ambiguidade de Maurice Merleau-Ponty. Partindo da compreensão de que a experiência vivida apenas pode ser adequadamente compreendida em mútua constituição com o mundo, tal perspectiva fenomenológica supera a dicotomia de interno versus externo, tão presente nos estudos sobre a subjetividade. Desta forma, a experiência suicida pode ser reconhecida como uma experiência mundana, uma vez que não é possível compreendê-la sem sua condição de imbricação com o mundo. Foram entrevistados seis pacientes psiquiátricos do sexo masculino que puderam descrever suas tentativas de suicídio por meio de entrevistas semiestruturadas. Identificando como cada colaborador compreendia suas experiências suicidas, foi possível descrevê-las sem as amarras teóricas dos estudos sobre tal tema. Pode-se perceber que a experiência suicida se caracteriza como uma vivência de aniquilamento existencial, e reconhecer, também, que as condições culturais e socioeconômicas em torno do suicídio devem ser sistematicamente consideradas e aprofundadas para que tal fenômeno humano possa ser melhor compreendido como um fenômeno mundano.
\end{abstract}

Palavras-chave: Suicídio; Fenomenologia; Psicologia humanista; Carl rogers; Merleau-ponty.

Abstract: This research has, as main objective, to understand the experience of suicide from a humanistic-phenomenological reference that proposes a conceptual review of Carl Rogers' humanistic psychology since Maurice Merleau-Ponty's phenomenology of ambiguity. Based on the understanding that lived experience can only be properly understood in mutual constitution with the world, such phenomenological perspective overcomes the dichotomy internal versus external, so present in studies on subjectivity. Thus, suicide experience may be recognized as a mundane experience, since it is not possible to understand it without its imbrication with the world. The research cooperators were male psychiatric patients who were able to describe their suicide attempts through semi-structured interviews. Identifying how each cooperator understands his suicidal experience, it was possible to describe them without the theoretical moorings of the studies on such theme. It is possible to perceive that suicidal experience is characterized as an experience of existential annihilation, and to recognize that cultural and socioeconomic conditions around suicide must be systematically considered and deepened for that human phenomenon can be better understood as a mundane phenomenon.

Keywords: Suicide; Phenomenology; Humanistic psychology; Carl rogers; Merleau-ponty.

Resumen: Esta investigación tiene como principal objetivo comprender la experiencia del suicidio desde un marco humanista-fenomenológico que propone una revisión conceptual de la psicología humanista de Carl Rogers desde la fenomenología de la ambiguidad de Maurice Merleau-Ponty. Con base en el entendimiento de que la experiencia sólo puede ser adecuadamente entendida en mutua constitución con el mundo, superase la dicotomía de interno y externo, como en los estudios sobre la subjetividad. Así, el experimento se conoce como una experiencia suicida mundana ya que no es posible comprender sin su condición de imbricación con el mundo. Los colaboradores eran hombres, pacientes psiquiátricos que fueron capaces de describir sus intentos de suicidio través de entrevistas semiestructuradas. Identificando de cómo los colaboradores comprenderan su experiencia suicida, ha hecho posible describirla sin los lazos teoricos que ya están presentes en el estudio sobre el tema. Se puede ver que la experiencia de un intento de suicidio se caracteriza por ser una experiencia existencial de la aniquilación. Entendemos que las condiciones culturáis y socioeconómicas en torno del suicidio necesitan ser consideradas y profundizadas sistemáticamente de manera que este fenómeno puede entenderse mejor como un fenómeno mundano.

Palabras-clave: Suicidio; Fenomenología; Psicología humanista; Carl rogers; Merleau-ponty. 


\section{Introdução}

O suicídio parece, num primeiro momento, algo absurdo, sem qualquer possibilidade racional de compreensão. Contudo, este é um fenômeno suficientemente presente na vida humana e que merece uma aproximação maior que possibilite um olhar mais atento a tudo o que o suicídio implica e representa, seja para a pessoa que tenta - e que, às vezes, consegue -, seja para as pessoas próximas, que são significativamente afetadas. Interessanos, em particular, compreender a experiência de tentar o suicídio sob o olhar de quem o intenta.

O suicídio é uma agressão deliberada que o indivíduo exerce contra si mesmo com o sentido de por um fim à sua vida (Cassorla, 1998). Evidentemente, há modos de autoagressão que não são considerados atos suicidas, mas que se mostram importantes para a compreensão das tentativas de suicídio, pois revelam um desinteresse significativo pela vida. Não apenas o ato extremo de tentar se matar concluído com êxito, mas, também, outros pequenos atos contra a própria vida podem ser entendidos como parte de uma tentativa suicida, embora nem sempre se possa dar conta disso. Embora esses pequenos gestos passem quase despercebidos no cotidiano das pessoas, eles servem como sinais de alerta de que "as coisas não andam boas" para esse indivíduo e que a possibilidade de uma tentativa suicida deve ser considerada, ainda que isso possa proporcionar desgaste aos que estão ao seu redor. Estar atento a tais simples atitudes pode ser muito útil no sentido de possibilitar uma escuta facilitadora da compreensão da angústia e de uma possível falta de vontade de viver.

A falta de sentido da vida pode ser um significativo componente na tomada de uma decisão violenta de se matar. Conforme Dutra (2000),

(...) o modo inautêntico de viver acarretará escolhas existenciais inadequadas, porque incompatíveis com o seu ser verdadeiro, levando a pessoa a uma existência marcada pelo fracasso, pela baixa autoestima, irrealização e infelicidade, gerando uma total incapacidade de amar e ser amado. Dá-se, então, o vazio existencial e a falta de sentido para a vida, que podem levar o jovem a, numa postura fatal, querer sair do vazio e tentar preencher esse vácuo em que se encontra, ainda que seja em direção a um desconhecido que lhe resgatará do sofrimento, ainda que seja ceifando a sua vida através de um ato de extrema violência, como o são o suicídio e a tentativa de suicídio (p. 100).

Dutra acrescenta que, "no desespero que surge desse contexto psicossocial, a morte surge como saída do sofrimento. A morte é a alternativa para calar a dor. A morte pode ser a alternativa para a solidão existencial que dilacera a vida” (p. 102). Essa escolha se torna extrema, no entanto, porque não permite ao indivíduo uma retomada de suas possibilidades existenciais. A falta de habilidade para lidar com a dor e o sofrimento parece colocar as pessoas diante de uma possibilidade quase inevitável de querer resolver seus problemas, eliminando-os consigo mesmas: resolver os problemas com a própria morte.

É comum ouvirmos pessoas falarem que já pensaram, alguma vez, em tentar se matar por estarem passando por um momento mais difícil em suas vidas, no qual houve alguma perda significativa ou por falta de perspectiva para viver. Acabam passando de um simples pensamento a uma ideia mais recorrente e, portanto, entram em risco real de suicídio.

As fantasias suicidas podem fazer parte do imaginário de muita gente. Werlang e Botega (2004) consideram "importante reconhecer as diversas fantasias sobre o suicídio, sejam elas conscientes ou não e o que essa possibilidade representa para essa pessoa" (p. 29). Há suicídios, por exemplo, em que o que estava mais presente era o desejo de controlar o momento da morte, como ocorre nas fantasias sobre os fatos relacionados à morte dos suicidas ou mesmo em relatos escritos que deixam, sugerindo comportamentos influenciadores de terceiros. Cada situação deve ser considerada de perto para obter o maior número de informações possíveis que sejam úteis ao trabalho de prevenção do suicídio.

Dentre as inúmeras fantasias suicidas, conforme estudo de Cassorla (2004), as que mais ocorrem podem ser reunidas no grupo daquelas que 'buscam outra vida' e aquelas em que há uma tentativa de reencontro ou de algum tipo de autopunição. Ele ressalta que, em várias culturas, há um culto, após a morte do indivíduo, em que se destaca a importância da vida, considerada plena. Essa ação parece contribuir com a formação de tais fantasias. Quanto à tentativa de reencontro, ela pode ser percebida como um desejo de se aproximar de Deus e gozar da felicidade eterna, ou, ainda, de algum ente querido que tenha morrido. Neste caso, a dor da perda parece angustiar a pessoa de forma a tornar a vida insuportável e indesejável. Outra fantasia comum é a vingança que o ato suicida produzirá sobre aqueles que lhe são próximos. Tal tentativa de vingança ocorre, muitas vezes, falseada em pedidos de perdão e desencargo de culpa, quando, na verdade, o que o suicida parece desejar é, exatamente, o contrário. Fantasias frequentes sobre o suicídio demonstram necessidade de pedir ajuda por conta do sofrimento que a pessoa está passando e que, sozinha, não consegue suportar. Nesses casos, nem sempre é fácil a quem está próximo detectar que a pessoa passa por tal dificuldade. Para Cassorla (2004), as fantasias suicidas costumam aparecer quando ocorre sofrimento sentido como terrível, não apenas emocional, mas também físico. É diante de um sofrimento intenso que a ideia de morte começa a ser considerada mais interessante do que a própria vida. 
Werlang \& Botega (2004) lembram que "alguns suicídios que poderiam ser considerados heróicos para uma determinada sociedade ressaltam a importância da cultura para a compreensão de sua execução" (p. 28). Tal destaque faz pensar na importância de uma determinada cultura e como ela considera o suicídio: "a importância de fatores culturais é evidente quando verificamos que as taxas de suicídio se mantêm mais ou menos constantes durante décadas em cada comunidade" (Werlang \& Botega, 2004, p. 28). Isto pode indicar uma influência de valores culturais sobre a tomada de decisão da pessoa de se suicidar, ainda que tal decisão pareça ser de natureza subjetiva e individual. Cada sociedade vai participar, à sua maneira, da recorrência dos suicídios em seu meio.

Uma tentativa de suicídio coloca a pessoa diante de um problema existencial significativo. Ela tem de responder a si mesma qual o valor que a vida tem para ela. Quem tenta contra a própria vida, seguramente, já não encontra valor nela. Quem sobrevive a uma tentativa suicida reorganiza tal saber de modo lento, mas nem sempre consegue resultados significativos. Foi o que revelou a pesquisa ${ }^{1}$ (Rocha, 2005) que descrevemos a seguir. A pesquisa aconteceu em um tradicional hospital psiquiátrico de Fortaleza, Ceará, Brasil. Quando entramos em contato com o serviço de psicologia do hospital, fomos prontamente acolhidos pelos gestores, que se disponibilizaram para qualquer necessidade de nossa investigação. Decidimos, por sugestão da psicóloga, entrevistar pacientes do sexo masculino, uma vez que este era o seu setor de intervenção e por eles se mostrarem mais colaborativos nas atividades promovidas pelo hospital. Ao todo, fizemos oito entrevistas semiestruturadas, das quais pudemos aproveitar seis delas, entre os pacientes que puderam descrever suas tentativas de suicídio.

Realizar a pesquisa no próprio local no qual tais pessoas tratavam seu adoecimento permitiu ampliar o olhar sobre a experiência suicida e seus aspectos sociais, o que não teria acontecido caso tais entrevistas acontecessem em suas residências. Nossa investigação pretendeu desenvolver um olhar compreensivo sobre o fenômeno das tentativas de suicídio, não o limitando a uma experiência individual e meramente subjetiva, que, muitas vezes, é sinalizado como fraqueza de quem o tenta. Evidentemente, apenas com a superação de tais preconceitos é que seremos capazes de compreender, de fato, como a tentativa suicida foi vivida pela pessoa.

Para tal fim, o método fenomenológico foi fundamental, uma vez que toma como ponto de partida a suspensão dos conhecimentos a priori que temos do mundo. Por trabalharmos com uma fenomenologia ambígua, foi possível, nessa tentativa de suspensão, reconhecer como o mundo é, também, constituinte de tal experiência. Nossa

\footnotetext{
1 Esta pesquisa foi aprovada pelo Comitê de Ética em Pesquisa (CEP) da Universidade de Fortaleza, sob o registro de $\mathrm{n}^{\circ}$ 05-317.
}

pesquisa considerou a perspectiva teórica da abordagem centrada na pessoa, de Carl Rogers (1961/1997), como uma referência importante na compreensão das experiências humanas, mas tentou superar seus limites, utilizando a perspectiva da fenomenologia ambígua de Maurice Merleau-Ponty (1961/2004; 1945/2006; 1964/2009). Os contornos da experiência de mundo expressados nos relatos das tentativas de suicídio pelos entrevistados nos apontaram elementos participantes do seu cotidiano que nem sempre são claros quando se pensa no fenômeno da tentativa de suicídio. Cada experiência vivida de tentativa de suicídio apresenta um pouco do mundo constituinte em que ela ocorreu. Desta forma, nosso interesse foi compreender como foram vividas as experiências das tentativas de suicídio das pessoas que participaram da pesquisa.

\section{O Homem, um Ser que se Experimenta}

Na contramão das perspectivas comportamentalistas, Rogers (1961/1997) entendia que a experiência é vivida de modo subjetivo, não apenas como resposta a um sentimento. As pessoas podem se afastar temporalmente do impacto que a experiência exerce ou exerceu sobre suas vidas, porém seu significado fica disponível como algo de profundo valor à condição humana. À medida que se torna possível entrar em contato, novamente, com os elementos significativos da experiência vivida, o ser humano se torna capaz de potencializar a sua condição de existente neste mundo, desdobrando-a em novos significados. De acordo com Rogers, a consciência de si mesmo se reduz a partir do momento em que a experiência é identificada com um sentimento, dada sua particularidade como consciência reflexiva. No momento em que a experiência é tomada como objeto de uma consciência reflexiva, ela perde sua potencialidade e se torna apenas rememoração de fatos. O vivido da experiência se extingue e dá lugar a uma condição de alheamento. $\mathrm{O}$ impactante da experiência é sua sólida ligação com o vivido. Deste modo, nenhum relato da experiência pode ser tomado distanciado do vivido que tal experiência produziu ou continua a produzir na pessoa. Mesmo quando o tat vivido já é passado para a pessoa, a experiência pode ser novamente significada.

A consciência da experiência vivida delimita a condição da pessoa àquilo que ela é. Seu modo de ser se forma e se reformula sob as articulações que a sua consciência (intencional) de si mesma possibilita. A experiência ajuda a pessoa a se tornar o que ela é, a exercer melhor suas potencialidades, o que, para Rogers (1961/1997), já faz parte da condição própria de ser pessoa. Para ele, "ser o que realmente se é implica ainda outros componentes. Um deles, que talvez já tenha sido sugerido, é a tendência do indivíduo para viver numa relação aberta, amigável e estreita com a sua própria experiência” (p. 196). 
A pessoa se torna capaz de lidar com os temores que possam surgir das experiências mais dolorosas e as compreende como sólidas oportunidades de se apropriar-se delas e ser ela mesma e crescer. Sua experiência se torna, nitidamente, um importante aliado nas escolhas que fará ao longo da vida. Quando a experiência é avaliada negativamente, a pessoa pode querer evitar novas situações por parecerem semelhantes. Assim, perde oportunidades de crescimento que seriam bastante significativas para ela, não fosse o receio que criou de novas experiências por julgá-las ameaçadoras. Rogers entende que "é apenas quando vivencia um aspecto de si mesmo negado até então, num clima de aceitação, que a pessoa pode tentar assumi-lo como parte de si mesmo" (p. 196). Por mais dolorosa que tenha sido uma experiência, um clima de aceitação possibilita novas maneiras de lidar com sua percepção e, inclusive, se abrir, novamente, a experiências que possam parecer arriscadas, embora não menos importantes.

Para Rogers (1961/1997), a experiência humana se constitui na atitude de se tornar o que se é. Rogers entende que "ser o que se é, é mergulhar inteiramente num processo, que a mudança encontra-se facilitada e, provavelmente, levada ao extremo, quando se assume o que verdadeiramente se é” (p. 200). A mudança é um processo fluido de novas escolhas, mais criativas e originadas de uma avaliação organísmica da experiência. Tornar-se uma pessoa é ser capaz de considerar suas experiências como possibilidades existenciais, pois suas escolhas passam a ser decorrentes do vivido dessas experiências e do significado que ele potencializa. Experimentar um novo vivido de uma experiência pode mudar o sentido que ela tem para a pessoa. Muitas vezes, a pessoa tende a se fechar quando a experiência lhe causa algum tipo de sofrimento na tentativa de evitar o contato, novamente, com esta dor. Este modo de lidar com o sofrimento afasta a pessoa da possibilidade de crescimento que tal experiência pode lhe oferecer. Assim, é comum que assuma posturas mais rígidas diante de seus sentimentos e das escolhas que faz na sua vida. Por outro lado, ao integrar a experiência à sua vida, a pessoa assume uma condição de escolha plena daquilo que pode se tornar. Nas palavras de Rogers (1961/1997), podemos entender melhor tal processo:

(...) em uma relação segura a defesa ou rigidez tende a ser substituída por uma abertura cada vez maior à experiência. O indivíduo se torna mais abertamente consciente de seus próprios sentimentos e atitudes conforme estes existam nele em um nível orgânico. Também se torna mais consciente da realidade conforme esta existe fora de si mesmo, ao invés de percebê-la em categorias preconcebidas (p. 130).

Rogers defende que a pessoa que emerge de um processo experiencial descobre, cada vez mais, que seu próprio organismo é digno de confiança, pois constitui um instrumento adequado para descobrir o comportamento satisfatório em cada situação imediata. Ele acredita que isso se torna uma tendência que se faz evidente na pessoa e passa a ser fonte de novas escolhas e decisões. $\mathrm{O}$ indivíduo passa a perceber, progressivamente, que esse foco de avaliação se encontra dentro de si mesmo: olha menos para os outros em busca de aprovação ou desaprovação, de padrões a seguir, de decisões e escolhas, e a avaliação que faz de si mesmo e das situações que quer viver emerge de uma apreciação genuína de sua experiência vivida, ou seja, de uma atitude de consideração com a própria experiência vivida.

Experimentar-se é ter uma consciência pré-reflexiva da condição humana nas escolhas vividas pela própria pessoa. É, ainda, privilegiar um tipo particular de experiência que a coloca numa relação inseparável consigo mesma. A pessoa não se põe como objeto de sua cognição, mas se experimenta como novidade assimilável e vivificante. A escolha revela a qualidade da experiência vivida, pois dela pode verificar o processo interno de seleção do que é mais saudável para o seu organismo e a consciência de realidade que depura de suas experiências. A partir de então, assume um nível de consciência pré-reflexiva como um novo critério avaliador da experiência. Nenhuma explicação é maior do que a própria experiência vivida e o significado que dela obtém. A consciência que advém da experiência produz um conhecimento suficiente para elaborar critérios avaliativos de seleção para novas experiências, sem que seja necessário ater-se a normas ou padrões previamente estabelecidos.

\section{O Referencial Humanista-Fenomenológico}

Merleau-Ponty (1945/2006) entende que é necessário superar as dicotomias presentes nas tentativas de compreensão da relação do homem com o mundo. Tais tentativas partem do princípio de que é possível entendê-los de modo distinto e separadamente, dicotomia claramente refutada por Merleau-Ponty. A partir desta posição, ele nos possibilita uma leitura isenta de psicologismo, pois não tenta explicar as experiências humanas como meramente subjetivas, nem tampouco cede à tentação de um olhar socializante, que tenta encontrar os mesmos motivos nas contingências de mundo. Para Merleau-Ponty (1945/2006),

(...) o que nos permite tornar a ligar o "fisiológico" e o "psíquico" um ao outro é o fato de que, reintegrados à existência, eles não se distinguem mais como ordem do em si e a ordem do para si, e de que são ambos orientados para um polo intencional ou para um mundo. O homem concretamente considerado não é um psiquismo unido a um organismo, mas este vai e vem da existência que ora se deixa ser corporal e ora se dirige aos atos pessoais (p. 129-130). 
Coelho Jr. e Carmo (1991) afirmam que a filosofia de Merleau-Ponty não nega a existência do 'mundo exterior', concepção marcante do idealismo: na verdade, MerleauPonty afirma que o mundo já está aí antes de qualquer reflexão. É, também, uma filosofia que não nega o 'mundo interior', como faz o empirismo. A superação dessas correntes faz do pensamento de Merleau-Ponty um marco de compreensão para uma fenomenologia enraizada na existência, superando posturas transcendentais ou pragmáticas de entendimento dos fenômenos humanos. Segundo Merleau-Ponty (1964/2009),

(...) quando uma de minhas mãos toca a outra, ao contrário, o mundo de cada uma se abre para o da outra, já que a operação é reversível à vontade, pertencendo ambas, como se diz, a um único espaço de consciência, pois um só homem toca uma única coisa por intermédio das duas. Mas para que minhas duas mãos se abram para um único mundo, não basta que sejam dadas a uma única consciência: ou então também desapareceria a dificuldade em pauta; sendo os outros corpos conhecidos por mim do mesmo modo que o meu seria ainda ao mesmo mundo que eu e ele nos reportaríamos. Não, minhas duas mãos tocam as mesmas coisas porque são as mãos de um mesmo corpo; ora cada uma delas possui sua experiência tátil (p. 137).

Este exemplo adotado por Merleau-Ponty é uma clara referência à ambiguidade de sua fenomenologia. Posiciona-se como ambiguidade inclusiva, uma vez que mantém a diversidade própria de cada elemento, sem reduzi-los em uma compreensão dicotômica. O homem é o mundo e ambos são mutuamente constituídos.

Merleau-Ponty (1961/2004) permanece fiel à posição de que somente uma fenomenologia ambígua é capaz de compreender a experiência humana como ela ocorre. Ele utiliza o trabalho do pintor francês Paul Cézanne para exemplificar como esta ambiguidade é favorável a tal intento. A não demarcação de um contorno rígido nos quadros de Cézanne é, para Merleau-Ponty, um exemplo significativo de como a experiência humana se constitui. Deste modo, apenas é possível compreendê-la imbricada no mundo:

(...) não marcar nenhum contorno seria retirar aos objetos sua identidade. Marcar um só seria sacrificar a profundidade, isto é, a dimensão que nos oferece a coisa, não como exposta diante de nós, mas como cheia de reservas e como uma realidade inesgotável. Eis porque Cézanne acompanhará, numa modulação de cores, a intumescência do objeto e marcará com traços azuis vários contornos (Merleau-Ponty, 1961/2004, p. 130).

Tendo como base a fenomenologia de Maurice Merleau-Ponty (1961/2004; 1945/2006; 1964/2009), a pers- pectiva humanista-fenomenológica tem elaborado uma revisão crítica das principais proposições conceituais da psicologia humanista, especificamente algumas compreensões da Abordagem Centrada na Pessoa, de Carl Rogers. Nesta revisão, faz uma crítica ao humanismo antropocêntrico, presente na visão de homem da psicologia humanista como um todo (Moreira, 2009). Esta noção de homem se assemelha a uma compreensão subjetivista, pois pouco reconhece a condição de mútua constituição com o mundo da experiência vivida. Por não considerar o pensamento de Rogers claramente fenomenológico, a perspectiva humanista-fenomenológica tenta aproximar as idéias de Merleau-Ponty, principalmente sua concepção de mundaneidade, das daquele, que fundamentam o fazer clínico. Assim, tenta evitar a estranha aproximação de uma visão de homem subjetivante a uma prática crítica mundana.

A mútua constituição do homem com o mundo, presente na idéia de carne de Merleau-Ponty, abre um fértil espaço para desdobramentos teóricos da psicologia em sua proposição metodológica e epistemológica. Esta noção entende que a mesma tessitura que compõe o homem compõe, também, o mundo. Assim, o homem não pode ser compreendido senão a partir desta mútua constituição. Em suma, a compreensão daquilo que é humano exige a compreensão de como tal fenômeno ocorre no mundo, uma vez que ambos se mostram, como fenômenos, imbricados e mutuamente constituídos. O que pretende, portanto, é a superação dos dualismos tão comuns no pensamento ocidental, como corpo versus mente, objetividade versus subjetividade, interno versus externo etc. Tal superação será possível apenas mediante um tipo de dialética sem fim, por meio da qual é possível reconhecer a inserção do homem no mundo.

A partir das proposições de Moreira (2007), é possível reconhecer que o pensamento dialético deve partir como pensamento de situação, localizado no mundo, eliminando aquilo que não é verdadeiro na experiência pré-reflexiva e superando a dicotomia individual versus social. Uma dialética circular permite uma constante revisão epistemológica, uma vez que todo e qualquer conhecimento está sempre aberto à experiência de mundo que o homem possa vivenciar. A partir deste referencial, fica evidente a necessidade de uma revisão das chamadas psicopatologias, apoiada em uma postura crítica sobre sua organização e interesses. Tal revisão, desenvolvida por Moreira e Sloan (2002), propõe uma psicopatologia compreendida de forma não dicotomizada, ou seja, que privilegie o caráter mundano da experiência vivida.

Para tanto, ela não pode ser individualista e sua compreensão deve resgatar as dimensões cultural, histórica e biológica do fenômeno psicopatológico. É também próprio desta maneira de pensar a psicopatologia não se restringir a determinada sintomatologia, mas trabalhar com a compreensão da experiência psicopatológica, evidencian- 
do o seu caráter de sofrimento, presente em tal condição, que existe para além do adoecimento propriamente dito. Assim, sua atitude fundamental é desideologizadora, ou seja, permite a compreensão da "patologia mental como culturalmente produzida, também a partir de processos ideológicos" (Moreira \& Sloan, 2002, p. 132). Quando se pensa na experiência de tentativas suicidas, considerando a referida revisão conceitual, é possível superar um olhar diagnosticador, que busca identificar as patologias organizadoras de tal fenômeno, como se ele se reduzisse a elas. Portanto, um ato suicida passa a ser compreendido em mútua constituição com o universo diversificado da experiência vivida, considerando todos os seus aspectos constituintes.

\section{Metodologia Utilizada na Pesquisa}

Moreira (2004) entende que a metodologia fenomenológica de pesquisa em psicologia e psicopatologia também sofre variações segundo o pensamento filosófico que as sustenta. Para ela, ao escolher como base o pensamento de um determinado filósofo, Husserl ou Merleau-Ponty, por exemplo, o pesquisador assume uma condição particular de sua pesquisa. O método fenomenológico assume nuanças sutis conforme o enfoque filosófico que a contemple. Porém, mesmo se tratando de pensamentos particulares, os princípios gerais da fenomenologia se mantêm os mesmos e servem como base para outras áreas do conhecimento. Moreira (2004) compreende um desses pressupostos básicos da fenomenologia, a redução, como um artifício para revelar o mundo, para se dar conta dele. Ela aponta que a fenomenologia evita qualquer idealismo transcendental e tem como destino a existência em sua facticidade.

A pesquisa em psicologia com base nos pressupostos metodológicos da fenomenologia logra êxito à medida que a experiência existencial é descrita, numa tentativa de intencionalidade com o mundo no qual a pessoa investigada vive. Qualquer significado construído a partir desta descrição apenas pode ser considerado em seu vínculo com o mundo. Para Moreira (2004), é um grande engano pensar a essência desvinculada do mundo. Desta forma, quando o sujeito fala de si mesmo, fala, ao mesmo tempo, de um mundo do qual faz parte. O conhecimento que se procura alcançar por meio da pesquisa fenomenológica advém da experiência dos sujeitos da pesquisa, e a verdade que se produz daí tem uma dinamicidade própria, como é dinâmica, também, a experiência desses sujeitos. Tal verdade é um movimento que se constitui na relação que o ser estabelece com o mundo, jamais devendo ser considerada completamente definida, estática. Moreira (2002) entende que o conhecimento é algo sempre inacabado, onde sua perspectiva tem uma postura política que desautoriza qualquer tipo de totalitarismo. Uma rigidez na compreensão e mesmo na constituição de tal conhe- cimento não atendem aos pressupostos metodológicos da fenomenologia.

As pessoas que participaram das entrevistas eram pacientes do Hospital Psiquiátrico São Vicente. Ao todo, entrevistamos seis pacientes homens, o que ocorreu dado o fato de a psicóloga do hospital ser responsável pelo acompanhamento da ala masculina. Eles foram selecionados previamente pelo hospital, que já tinha conhecimento dos que haviam tentado suicídio. Os pacientes foram informados da natureza da pesquisa e de seus objetivos e, após terem sido informados sobre os procedimentos da entrevista e se disponibilizado a participar, assinaram um termo de consentimento, autorizando a utilização das informações na pesquisa.

As entrevistas aconteceram em uma sala reservada, dentro do próprio hospital, o que permitiu sua realização sem interrupções externas. Todas foram gravadas e transcritas, e, posteriormente, os dados foram submetidos à análise compreensiva. Os nomes foram alterados para garantir maior privacidade às pessoas entrevistadas. As entrevistas transcritas foram divididas e agrupadas em unidades temáticas de sentido, destacando como, para cada pessoa, a experiência de tentar se matar repercutiu em suas vidas. Agrupamos os depoimentos em temas comuns, sendo possível observar a singularidade das repostas e, ao mesmo tempo, a semelhança da experiência vivida por cada uma.

\section{Resultados e Discussão}

A pesquisa destacou a importância de alguns fatores determinantes na compreensão das tentativas de suicídio em pacientes psiquiátricos, dentre eles, o contexto sócio-familiar, os métodos escolhidos nas tentativas de suicídio e a experiência vivida numa situação de morte, culpa e aniquilamento. Para Cassorla (1998), não podemos apontar uma única causa para o suicídio, pois é um fenômeno que ocorre como culminância de diversos eventos e fatores, como os sociais, culturais, biológicos e psicológicos. Por conta de sua complexidade, o fenômeno do suicídio se constitui um grande desafio para sua compreensão.

\subsection{Contexto Sociocultural: Família, Religião e Drogas}

No contexto das relações sociais, a família assume um papel importante no processo de tomada de decisão da tentativa de suicídio, seja pelo completo desconhecimento do que se passa com o familiar que pensa em tentar o suicídio, seja por atitudes que denotam desconsideração pela condição em que ele se encontra. Geralmente, os familiares não sabem como acompanhar um parente que se encontra em tal situação. As primeiras opções que têm se apresentado para lidar com este fenômeno são o 
refúgio na prática religiosa e o apoio circunstancial do hospital psiquiátrico. Em ambos os casos, a iniciativa parte, em geral, dos familiares que buscam algum tipo de apoio para lidar com a situação. É comum que a família tenda a reduzir a tentativa suicida a um ato de loucura, inexplicável e sem motivo algum que possa justificá-la. A reação da família costuma ser insistir na idéia de que seu parente enlouqueceu e, a partir daí, ocorre a pressão pela internação em um hospital psiquiátrico. O depoimento de um participante da pesquisa demonstra como tal situação se torna um duplo incômodo para a pessoa que, por um lado, precisa lidar com sua angústia de não querer mais viver e, por outro, não encontra apoio no meio familiar:

“(..) quando eu falava pra minha mulher que pensava em morrer, ela dizia que eu era louco, que eu não sabia o que estava falando. Essas coisas não acontecem, não, mas a gente nota quando está em depressão. Depois disso, todo mundo só queria me botar no médico, me internar" (Pedro).

Para Werlang e Botega (2004), "tanto o indivíduo em geral quanto o suicida não podem ser considerados fora de seu ambiente familiar e social. Cada pessoa está em interação intensa com os outros membros da família e da sociedade” (p. 85). Os fenômenos humanos demandam uma compreensão sistêmica, não podendo ser considerados isoladamente do contexto no qual emergem. A família e a sociedade nas quais tais pessoas vivem têm papel fundamental em sua condição suicida.

A orientação religiosa, muitas vezes, considera a possibilidade da tentativa suicida como uma manifestação demoníaca de quem não sabe o que fala ou faz. Nesses casos, é costume haver a intervenção de um representante religioso, desenvolvendo rituais que amenizem o peso dos pensamentos de morte da pessoa. Além disso, a pessoa sofre um forte sentimento de culpa por seu ato, uma vez que se colocou contrária aos desígnios divinos. O suicida amargaria o peso de uma vida de pecado e de sofrimento após a morte. Angerami (1986) relembra que todas as formas de suicídio são condenadas pela Igreja Católica, desde o século XIII e que o Código de Direito Canônico, de 1918, promulgado pelo papa Bento XV, definia como punição ao suicida a privação da sepultura. Considerações religiosas podem ser identificadas no depoimento de outro participante da pesquisa:

“(...) eu fui crente e o pastor dizia que, uma vez com Deus, se eu saísse da Igreja, eu sairia com sete demônios e nunca mais teria paz de espírito. As pessoas da Igreja me viam falando sozinho e achavam que eu não estava dizendo coisa com coisa e me chamavam de doido, que era para tirar o demônio de mim” (João).
Outro aspecto decisivo na constituição da experiência suicida, presente na história de vida da maior parte das pessoas entrevistadas, é o consumo de drogas. Este fato põe a análise das tentativas de suicídio diante da necessidade de considerar o efeito das drogas sobre o comportamento humano. Este é um fator que não pode ser analisado isoladamente, antes como um importante componente social presente na escolha de se matar. Um participante destacou o impacto das drogas nas suas relações sociais e na constituição da condição psiquiátrica que passou a desenvolver:

“(...) a primeira tentativa de suicídio, eu morava em São Paulo. Tava tudo bem pra mim, eu tinha emprego. Aí, eu comecei a usar droga. Eu já usava droga aqui. Quando saí daqui, eu era usuário de droga; lá, eu continuei usando droga. Eu usava 'crack', maconha, usava 'aranha', qualquer tipo de droga. Eu, de repente, comecei a ver todo mundo me criticando - 'diabo, diabo, diabo! - e eu acabei enlouquecendo (Francisco).

\subsection{Tentando se matar: métodos escolhidos nas ten- tativas suicidas}

As pessoas entrevistadas tentaram o suicídio mais de uma vez e de formas diferentes. O meio que mais se destacou foi o enforcamento, que ocorria, geralmente, no próprio quarto da pessoa. O fácil acesso a meios letais, principalmente substâncias tóxicas e armas de fogo, pode ser considerado um facilitador importante nas tentativas suicidas. Um dos entrevistados destacou que sua tentativa de suicídio por enforcamento foi apenas mais uma que não deu certo, depois de várias, embora, algumas vezes, tenha ficado apenas na ideação:

“(...) a primeira tentativa, eu morava em São Paulo. Eu fui tentar pular de um passadiço - pular, não - eu me sentei, fui me afastando, me afastando até que um policial foi lá e me tirou. A segunda tentativa foi em casa (Fortaleza). Eu tava num descontrole: fiz tudo errado. A minha madrasta tava com raiva de mim: eu coloquei, no feijão, cocô de rato dentro do feijão que ela ia fazer um baião. Ela tava com raiva de mim. Eu tentei com uma corda, mas não deu certo, também. Foi ela que me salvou. Ela tinha ido comprar cigarro e, quando ela chegou, eu estava na corda. Ela chegou e cortou. Um rapaz, perto lá de casa, me ressuscitou. A outra tentativa, eu tomei veneno, mas era um tipo de veneno de matar carrapato. Eu não sei nem se fez mal a mim, ou se não fez. Aí, eu comecei a ver coisa, a ver um bocado de coisa, ver gente entrar por um canto e sair por um outro, ver um bocado de coisa” (Paulo). 
A hospitalização mostra-se pouco eficaz no acompanhamento dos pacientes suicidas, uma vez que prioriza a medicalização, mas há poucos recursos para lidar com a vontade de se matar. Um dos entrevistados tentou, mais de uma vez, o suicídio, uma delas no hospital, tentando se precipitar do telhado, e outra tentativa em casa, fazendo uso de enforcamento. A chegada da mãe, naquele momento, foi o que evitou o óbito:

“(...) eu tentei suicídio, duas vezes. Uma, no hospital: tentei pular de cima do telhado. Não pulei porque não consegui. Eles me seguravam e eu dizia que queria ir embora, mas eu queria era me matar: não queria ir embora do hospital. A outra, peguei uma corda pra me enforcar, mas minha mãe chegou, chamou os vizinhos, que me tiraram de lá” (Pedro).

Werlang e Botega (2004) discutem o fato de as taxas de suicídio serem significativamente maiores entre os homens, apontando, como uma das causas de tal fenômeno, as formas de tentativas de suicídio que os homens escolhem, geralmente bem mais letais do que os meios predominantemente escolhidos pelas mulheres. Cabe-nos, contudo, destacar o fácil acesso a meios letais disponíveis na sociedade, principalmente as armas de fogo, bem como a necessidade de políticas públicas que limitem tal acesso e criem condições preventivas mais eficazes do suicídio.

\subsection{O que Experimentam nas Tentativas Suicidas}

O que representa uma tentativa suicida na vida de uma pessoa apenas é possível identificar a partir da compreensão de como tal experiência foi vivida e que impacto ela gerou na pessoa que tentou se matar. As pessoas entrevistadas revelaram dificuldade de conversar com seus familiares sobre o quê se passava com elas e sobre sua intenção de se matar. Mesmo sendo tão significativo para elas, tal experiência foi vivida na solidão de seus pensamentos, sem se sentirem capazes de compartilhar com outras pessoas o que atravessavam. Um participante da pesquisa destacou sua situação:

“(..) eu nunca tinha pensado em me matar. Foi a primeira vez. Também não falei com ninguém sobre isso. Eu nunca falei pra ninguém que pensava em me matar. Nunca deixei nenhum bilhete: sempre foi tudo "na doida mesmo". Eu não pensei em dizer nada para ninguém. Foi uma idéia que me veio à cabeça" (Francisco).

A condição de hospitalização psiquiátrica revelou uma característica dos pacientes suicidas: em geral, eles apresentaram algum quadro de alucinação auditiva, acompanhado de sintomas persecutórios. Quase sempre, as vozes estimulavam a tentativa suicida e, embora causassem algum desconforto à pessoa, acabavam se tornando a única forma de 'comunicação' com sua intenção de se matar. Um entrevistado revelou um conflito interno muito forte: enquanto as vozes lhe diziam que este mundo não valia a pena, "em seu coração”, havia uma desconfiança sobre a veracidade do que lhe diziam as vozes:

“(...) eu, drogado demais, escutava vozes. As vozes chegavam para mim e falavam: 'vem pra cá, pra esse mundo, aqui, que esse mundo, aqui, é mais 'massa'. É um mundo melhor'. Essas vozes queriam que eu fosse para onde estava minha tia, que morreu com 27 anos, de HIV. Tinha alguma coisa, 'no meu coração', que me dizia que não era para eu ir, que isso era só conversa, assim, mentira das vozes" (Paulo).

As tentativas de suicídio repercutem de modo diferente e singular sobre cada pessoa, ainda que algumas manifestações sejam comuns à maioria dos casos. Tal singularidade permite-nos compreender o suicídio como uma ação de um indivíduo em um contexto sociocultural, no qual se encontram mutuamente implicados (Merleau-Ponty, 1961/2004; 1945/2006; 1964/2009). Esta mútua constituição tanto evidencia a própria condição mundana da experiência humana, quanto destaca a impossibilidade de um estudo sobre o tema que não seja multidisciplinar. Não se trata de encontrar causas para o fenômeno do suicídio, mas de compreendê-lo na sua imbricação com o mundo em que se constitui o indivíduo que pensa e, por vezes, tenta se matar.

Foi comum, no depoimento das pessoas entrevistadas, haver referências a sensações de mal-estar ou de angústia. Algumas vezes, tal experiência vivida de malestar era tão forte que parecia ser orgânica para alguns entrevistados:

“(...) eu comecei a sentir um 'negócio' estranho, uma ‘coisa' ruim, minha cara ardendo. A minha sensação era como se eu estivesse derretendo. Eu estava mal, com uma agonia: o corpo suava e começava a tremer. Comecei a ficar zonzo e me encostar na parede. Se eu morresse, ia ser um fim só pra mim. Aí, eu tentei pra aliviar o sofrimento. Hoje, eu não penso nisso mais, não" (José).

Cassorla (1998) entende que o suicida quer viver e morrer ao mesmo tempo. Portanto, sua experiência é mais complexa do que um simples processo de desmotivação, por exemplo. Entretanto, é uma decisão que atinge bem mais do que o seu próprio corpo. A experiência suicida produz um impacto muito grande, tanto sobre a pessoa que o tenta, quanto sobre seus familiares. A agressão deliberada contra a própria vida faz vir à tona o niilismo em que, muitas vezes, se sustenta a existência, tornando-a 
uma vida sem sentido. O medo assumiu um lugar comum entre as pessoas entrevistadas, um medo diverso, que se manifestava como medo de morrer, de enlouquecer, ou mesmo de ficar só, ser abandonado.

Também foi comum a expressão de falta de perspectiva para lidar com as situações de conflito em que se encontravam. Um entrevistado deixou a impressão nítida do quanto o suicídio pode ser decorrente de uma experiência niilista da vida e de como a morte pode se apresentar como uma alternativa interessante para aqueles que vivenciam tal estado. A perda de sentido da vida é uma antecipação das tentativas de suicídio:

“(..) pra mim, a vida não tem sentido mais. Pra mim, sinceramente, eu preferia a morte. Se eu morresse, eu teria paz” (Raimundo).

\section{Considerações Finais}

Geralmente, as tentativas de suicídio são mal compreendidas pelas pessoas, muito em função dos inúmeros fatores associados a esta experiência, sejam eles históricos ou culturais. Assim, familiares e amigos acabam por fazer uma análise superficial da situação em que se encontra o suicida e concluem que a tentativa aconteceu por alguma condição anterior, vivida pelo indivíduo, como uma possessão demoníaca ou a perda da razão, por exemplo.

As tentativas de suicídio repercutem de modo diferente e singular sobre cada pessoa, ainda que algumas considerações epidemiológicas se apresentem na maioria dos casos. Tal singularidade nos permite compreender o suicídio como uma ação vivida num contexto sociocultural determinado. Com base no referencial humanistafenomenológico, compreendemos que a relação entre as tentativas de suicídio e o contexto em que vive a pessoa que as comete é mutuamente constituída. Portanto, não podemos privilegiar uma perspectiva, individual ou social, sem que comprometamos a compreensão do fenômeno do suicídio.

Para Moreira (2007), "este homem que sempre está entrelaçado com o mundo, não é o centro do mundo. Ele o constitui tanto quanto o mundo constitui a ele, de tal modo que não existe um centro" (p. 107). A superação de tais dicotomias constitui um olhar diferenciado sobre a experiência vivida humana, que é compreendida em sua ambiguidade. Desta forma, a tentativa suicida, assim reconhecida, deixa de ser concebida como um fenômeno vivido por uma subjetividade adoecida e passa a ser compreendida como um fenômeno mundano.

Evidentemente, a clínica psicológica compreende a importância da atenção preventiva nos cuidados com os pacientes suicidas, porém entende que a vontade de morrer é uma experiência legítima e que merece ser acompanhada como qualquer outra experi- ência humana. Contudo, tal posição não abre espaço para a concordância com o ato letal. Experimentar-se é uma forma de poder significar essa vontade de uma nova maneira, descobrindo novos sentidos que justifiquem viver.

A agressão deliberada contra a própria vida revela a condição de aniquilamento em que se encontra a pessoa, mas faz atentar, também, à significação que atribui às suas relações e o quanto elas participam de seu aniquilamento existencial, não apenas para sua condição pessoal. Uma existência despotencializada deixa a vida com pouco significado, fazendo a morte parecer a opção mais viável para resolver seus problemas. A experiência vivida em sua ambiguidade nos remete a uma compreensão da tentativa suicida como um fenômeno humano complexo, que exige um adequado preparo de profissionais que pretendem ajudar as pessoas em sua condição, sem deixar de lado as necessárias mudanças sociais para atingir tal objetivo.

Nossa pesquisa proporcionou um olhar mais atento ao suicídio como um fenômeno ambíguo, não como uma experiência meramente subjetiva, que necessita de cuidados estritamente psicológicos. As demandas sociais e culturais precisam ser reconhecidas com igual importância para uma adequada compreensão do suicídio, revelando-o como um fenômeno mundano.

\section{Referências}

Angerami, V. (1986). Suicídio: uma alternativa à vida, uma visão clínica-existencial. São Paulo: Traço.

Cassorla, R. (1998) (Coord.). Do suicídio: estudos brasileiros. Campinas: Papirus.

Cassorla, R. (2004). Suicídio e autodestruição humana. Em B.Werlang \& N.Botega (Orgs.), Comportamento suicida (pp. 21-35). Porto Alegre: Artmed.

Coelho Jr., N., \& Carmo, P. S. (1991). Merleau-Ponty: filosofia como corpo e existência. São Paulo: Escuta.

Dutra, E. (2000). Compreensão de tentativas de suicídio de jovens sob o enfoque da abordagem centrada na pessoa. Tese de doutorado. São Paulo: Instituto de Psicologia da Universidade de São Paulo.

Merleau-Ponty, M. (2004). O olho e o espírito. São Paulo: Cosac \& Naify (Original publicado em 1961).

Merleau-Ponty, M. (2006). Fenomenologia da percepção. São Paulo: Martins Fontes (Original publicado em 1945).

Merleau-Ponty, M. (2009). O visível e o invisível. São Paulo: Perspectiva (Original publicado em 1964).

Moreira, V. (2004). O método fenomenológico de MerleauPonty como ferramenta crítica na pesquisa em psicopatologia. Revista Psicologia: Reflexão e Crítica, 17 (3), 447-456. 
Moreira, V. (2007). De Carl Rogers a Merleau-Ponty: a pessoa mundana em psicoterapia. São Paulo: Annablume.

Moreira, V. (2009). Clínica humanista-fenomenológica: estudos em psicoterapia e psicopatologia crítica. São Paulo: Annablume.

Moreira, V., \& Sloan, T. (2002). Personalidade, ideologia e psicopatologia crítica. São Paulo: Escuta.

Rocha, M. A. S. (2005). Tentando morrer: uma compreensão existencial-fenomenológica de tentativas de suicídio. Dissertação de mestrado. Fortaleza: Programa de Pós-Graduação em Psicologia da Universidade de Fortaleza.

Rogers, C. R. (1997). Tornar-se pessoa ( $5^{\mathrm{a}}$ ed.). São Paulo: Martins Fontes (Original publicado em 1961)

Werlang, B., \& Botega, N. (2004) (Orgs). Comportamento suicida. Porto Alegre: Artmed.
Márcio Arthoni Souto da Rocha - Professor da Universidade Federal do Ceará (UFC - Campus Sobral), Mestre e Doutorando em Psicologia pela Universidade de Fortaleza (Unifor). É membro do Laboratório de Psicopatologia e Psicoterapia Humanista-Fenomenológica Crítica APHETO.E-mail: arthoni@yahoo.com.br

Georges Daniel Janja Bloc Boris - Psicólogo, Mestre em Educação e Doutor em Sociologia pela Universidade Federal do Ceará (UFC). Professor titular do Curso de Psicologia e do Programa de Pós-Graduação em Psicologia da Universidade de Fortaleza (Unifor). Coordenador do Laboratório de Psicopatologia e Psicoterapia Humanista-Fenomenológica Crítica - APHETO.E-mail: geoboris@unifor.br

Virginia Moreira - Professora Titular do Programa de Pós-Graduação em Psicologia da Universidade de Fortaleza, onde coordena o APHETO - Laboratório de Psicopatologia e Psicoterapia Humanista Fenomenológica Crítica. É Doutora em Psicologia Clínica pela PUC-SP, com Pós-Doutorado em Antropologia Médica por Harvard University. É membro da World Association of Person Centered and Experiential Psychotherapy e da Associação Universitária de Pesquisadores em Psicopatologia Fundamental. Endereço Institucional: Universidade de Fortaleza, Mestrado em Psicologia. Av. Washington Soares 1321 (Bairro Edson Queiroz). CEP 60811-905. Fortaleza/CE. E-mail: virginiamoreira@unifor.br

Recebido em 12.02.12

Primeira Decisão Editorial em 23.05.12

Aceito em 14.06 .12 